\title{
INCLUSÃO DE ESTUDANTES PÚBLICO ALVO DA EDUCAÇÃO ESPECIAL UTILIZANDO RECURSOS TECNONOLÓGICOS DIGITAS DE INFORMAÇÃO E COMUNICAÇÃO.
}

\author{
Luiz Fernando da Silva Lourençot, Elisa Tomoe Moriya Schlüzen, Danielle Aparecida do Nascimento \\ dos Santos
}

Universidade Estadual Paulista Júlio de Mesquita Filho - UNESP - Presidente Prudente. E-mail: luizfernando slourenco@hotmail.com

\section{RESUMO}

O presente artigo apresenta um trabalho desenvolvido com dois estudantes público-alvo da Educação Especial (EPAE. Um com Paralisia Cerebral e outro com Déficit Intelectual, sendo que em ambos os casos os estudantes apresentam dificuldades de aprendizagem. Esses estudantes frequentam o Centro de Promoção para Inclusão Digital, Escolar e Social (CPIDES) da Faculdade de Ciências e Tecnologia (FCT/Unesp) campus de Presidente Prudente/SP. As atividades de acompanhamento são vinculadas ao grupo de pesquisa Ambientes Potencializadores para a Inclusão (API) visando a inclusão social, digital e escolar de pessoas com deficiência. Para realizar o acompanhamento, são utilizados recursos de tecnologia como Objetos de Aprendizagem, para a realização de atividades contextualizadas para os estudantes. A primeira fase consiste no diagnóstico dos estudantes, onde abordamos o conceito da Paralisia Cerebral (PC) e Déficit Intelectual (DI), pois é de suma importância para uma intervenção pedagógica eficaz. A partir do diagnóstico são realizadas observações para compreensão das principais habilidades dos estudantes, visando minimizar as dificuldades ocasionadas pelas deficiências e suas implicações para o ensino e a aprendizagem dos mesmos. As atividades desenvolvidas são fundamentadas na abordagem Construcionista, Contextualizada e Significativa (CCS) de ensino, onde os temas de ensino partem dos assuntos de interesse dos educandos. Os resultados atingidos pelos estudantes demonstram que é possível a intervenção pedagógica com o auxilio de tecnologias e outros materiais pedagógicos.

Palavras-chave: Uso de Tecnologias Digitais de Informação e Comunicação, Processo de Aprendizagem, Inclusão de Pessoas com dificuldades de aprendizagem.

\section{INTRODUÇÃO E OBJETIVOS}

O grupo de pesquisa Ambientes Potencializadores para a Inclusão (API) agrega pesquisadores da área de formação de professores, que desenvolvem pesquisas sobre inclusão digital, social e escolar de estudantes público-alvo da Educação Especial (EPAEE), tendo como parâmetro o uso de tecnologias em uma abordagem Construcionista, Contextualizada e Significativa (CCS).

Para Schlünzen (2000, p. 82) um ambiente CCS,

É um ambiente favorável que desperta o interesse do aluno e o motiva a explorar, a pesquisar, a descrever, a refletir, a depurar as suas ideias. [...] As informações que são significativas para o aluno podem ser transformadas em conhecimento [...] O aluno consegue descobrir a relação com tudo que está aprendendo, a partir de seus interesses individuais dentro do seu contexto. 
Assim, são realizados acompanhamentos junto a estudantes com deficiências, onde são realizadas atividades de uso de recursos como: Softwares educativos, desenvolvidos no próprio grupo de pesquisa ou por terceiros, Objetos de Aprendizagem e internet. Nesse mesmo sentido, os acompanhamentos não se limitam somente ao uso desses recursos, ficando a cargo dos estagiários (discentes de licenciatura), a implementação de outros recursos pedagógicos além da tecnologia.

Segundo Sassaki, (1997)

Entende-se inclusão social como o processo pelo qual a sociedade se adapta para poder incluir, em seus sistemas sociais gerais, pessoas com necessidades especiais e, simultaneamente, estas se preparam para assumir seus papéis na sociedade. A inclusão social constitui, então, um processo bilateral no qual as pessoas, ainda excluídas, e a sociedade buscam, em parceria, equacionar problemas, decidir sobre soluções e efetivar a equiparação de oportunidades para todos.

Sendo assim, o trabalho desenvolvido com os estudantes tem como viés amenizar as dificuldades de aprendizagem ocasionadas por diferentes motivos. Pois, com a obtenção de resultados positivos no processo de aprendizagem, os educandos se sentem mais seguros e capazes para buscarem seu espaço dentro da sociedade e como consequência, serem incluídos.

As dificuldades de aprendizagem podem ser ocasionadas por motivos biologicos do ser humano ou por elementos emocionais do dia a dia do individuo. Portanto, se faz importante que esses motivos sejam previamente descobertos com o intuito de amenizar e auxiliar o decorrer do processo educativo do mesmo, percebendo assim se essa dificuldade se associa a algum desses motivos.

Neste trabalho em questão no trabalho desenvolvido com dois estudantes, o primeiro com (PC) Paralisia Cerebral, e outro com (DI) Déficit Intelectual, foi realizado previamente um levantamento sobre as patologias em questão. Quanto às informações e dados estatísticos atinentes à PC, encontrados na Associação Brasileira de Paralisia Cerebral, indicam que a PC afeta em torno de 2 a 3 casos por 1000 nascidos vivos, em países desenvolvidos. Paralisia Cerebral (PC) é um termo geral que engloba manifestações clínicas muito variadas, que têm em comum a dificuldade motora em consequência a uma lesão cerebral. Para que uma criança com dificuldade motora tenha o diagnóstico de PC, é necessário:

1. Que a lesão neurológica tenha acontecido durante a fase de desenvolvimento do Sistema Nervoso Central (SNC) (fase que vai desde o momento da concepção até os 2 anos de idade).

2. Que a lesão neurológica não seja uma lesão progressiva. A criança vai apresentar 
mudanças decorrentes de seu crescimento e amadurecimento, mas a lesão em si é estacionária, ou seja, não vai agravar, tampouco desaparecer.

Já a Deficiência Intelectual (DI) é conhecida por problemas com origem no cérebro e causadora de baixa produção de conhecimento, dificuldade de aprendizagem e baixo nível intelectual. Além de limitações no funcionamento adaptativo de algumas habilidades como acadêmicas, de trabalho, lazer, saúde e segurança. Ao analisarmos a semântica do termo DI, é possível afirmar que o mesmo prevê a denotação de pessoa que apresenta impedimento ou limitação na função fisiológica, especificamente intelectual, sendo este um dos componentes da função mental.

Com relação às pessoas com DI é fato que as mesmas possuem limitações, mas se respeitadas suas limitações e potencializada suas habilidades, conseguem realizar diversas atividades que são comuns ao nosso cotidiano.

Considerando esse panorama, verificamos que as tecnologias digitais vêm auxiliando as pessoas com deficiências no processo educacional, em especial aquelas que por algumas limitações, encontram dificuldades em realizar atividades como ler, escrever, e até manusear certos objetos. Nesse sentido, a tecnologia, quando usado como recurso educacional, proporciona avanços no processo de aprendizagem. Conforme relata Kenski (2007).

A imagem, o som e o movimento oferecem informações mais realistas em relação ao que está sendo ensinado. A autora acrescenta, quando bem utilizadas, provocam a alteração dos comportamentos de professores e alunos, levando-os ao melhor conhecimento e maior aprofundamento de conteúdo estudado (KENSKI, 2007, p.45).

Neste panorama verificamos que as TIC's vêm auxiliando as pessoas no processo educacional, em especial aquelas que por algumas limitações, encontram dificuldades em realizar atividades como ler, escrever, e até manusear certos objetos. Nesse sentido, o computador, quando usado como ferramenta educacional, proporciona avanços no processo de aprendizagem.

Acredita-se que a utilização das TIC'S no processo de ensino e aprendizagem auxilia o educador na elaboração das atividades, e em relação ao educando na realização das tarefas propostas, pois o software educativo proporcionará um maior entendimento por parte do aluno dos conceitos abordados, já que ele terá a oportunidade de vivenciar tais situações empiricamente.

Nesta perspectiva, utilizamos tecnologias no processo de ensino e aprendizagem, sendo que estas nos auxiliam na elaboração das atividades que são desenvolvidas com os dois estudantes, e 
em relação a eles na realização das propostas, uma vez que os softwares educativos podem proporcionar um maior entendimento dos conceitos abordados.

Sendo assim o objetivo do trabalho é possibilitar a inclusão desses alunos em questão utilizando dos recursos tecnológicos, mas entendendo também que os recursos tecnológicos sozinhos não conseguirão proporcionar que os mesmos sejam incluídos de fato pois deve ser levado em conta vários fatores.

\section{MATERIAIS E MÉTODOS}

Esta pesquisa foi realizada mediante o projeto que encontra-se cadastrado no Comitê de Ética em Pesquisa (CEP) sobre protocolo 106/2009.

No inicio dos atendimentos realizamos entrevistas com os responsáveis e obtivemos dados relacionados à convivência do estudante com sua família, suas dificuldades, os objetivos que esperam alcançar com os atendimentos, entre outros dados. Através destes dados são elaboradas atividades em que as Tecnologias Digitais de Informação e Comunicação (TDIC) são utilizadas, a fim de minimizar as dificuldades e desenvolver suas potencialidades. Antes de iniciarmos à intervenção, realizamos um levantamento bibliográfico sobre as características e especificidades que devem ser exploradas no ensino dos EPAEE. Os planos de atendimentos são baseados na metodologia de trabalho com projetos, tendo como base Objetos de Aprendizagem, como "Fazenda Rived", que podem ser encontrados no Banco Internacional de Objetos Educacionais (BIOE). Além de utilizarmos esses recursos, são feitas adaptações pedagógicas usando TA como auxílios de hardware e jogos educativos adaptados.

Para atingir o objetivo proposto, realizamos no primeiro momento um diagnóstico, viabilizado por uma aproximação com os estudantes e seus responsáveis, a fim de que seja elaborado um quadro das suas principais habilidades e a detecção das suas dificuldades, potencialidades e interesses. Após o diagnóstico, é elaborado um programa de atividades semanais e no desenvolvimento dessas atividades são utilizadas Tecnologias Digitais de Informação e Comunicação (TDIC). Os Softwares educacionais utilizados com esses dois estudantes são "Fazenda Rived", "Um Dia de Compras" e "Festa de Aniversário", e em conjunto com os mesmos são utilizados materiais pedagógicos como jogos educativos, atividades de escrita e leitura, trabalhos manuais, entre outros, que visam minimizar as dificuldades de cada estudante para assim desenvolver suas potencialidades. 


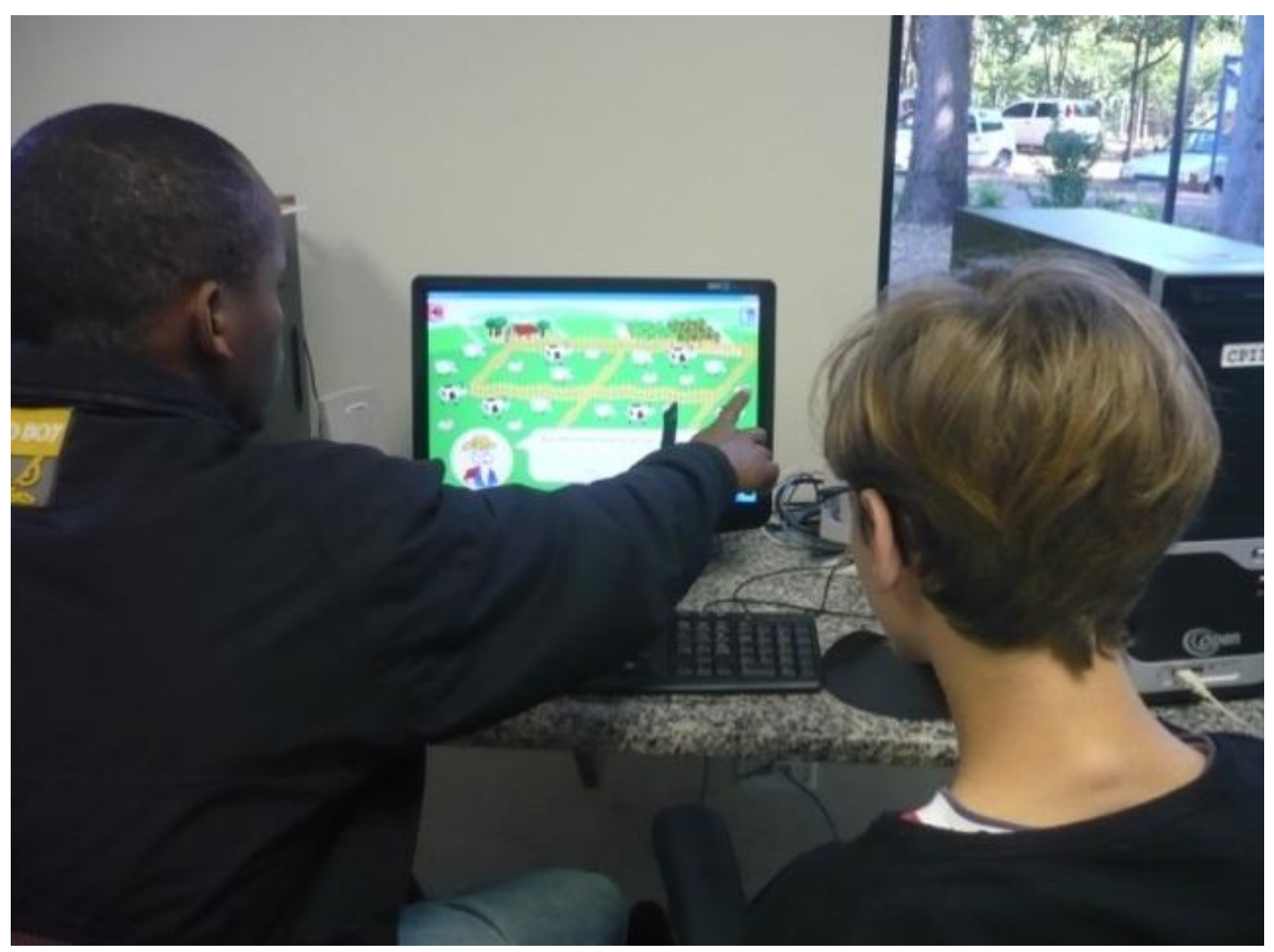

Figura1. Objeto educacional Fazenda Rived /noções básicas de contagem.

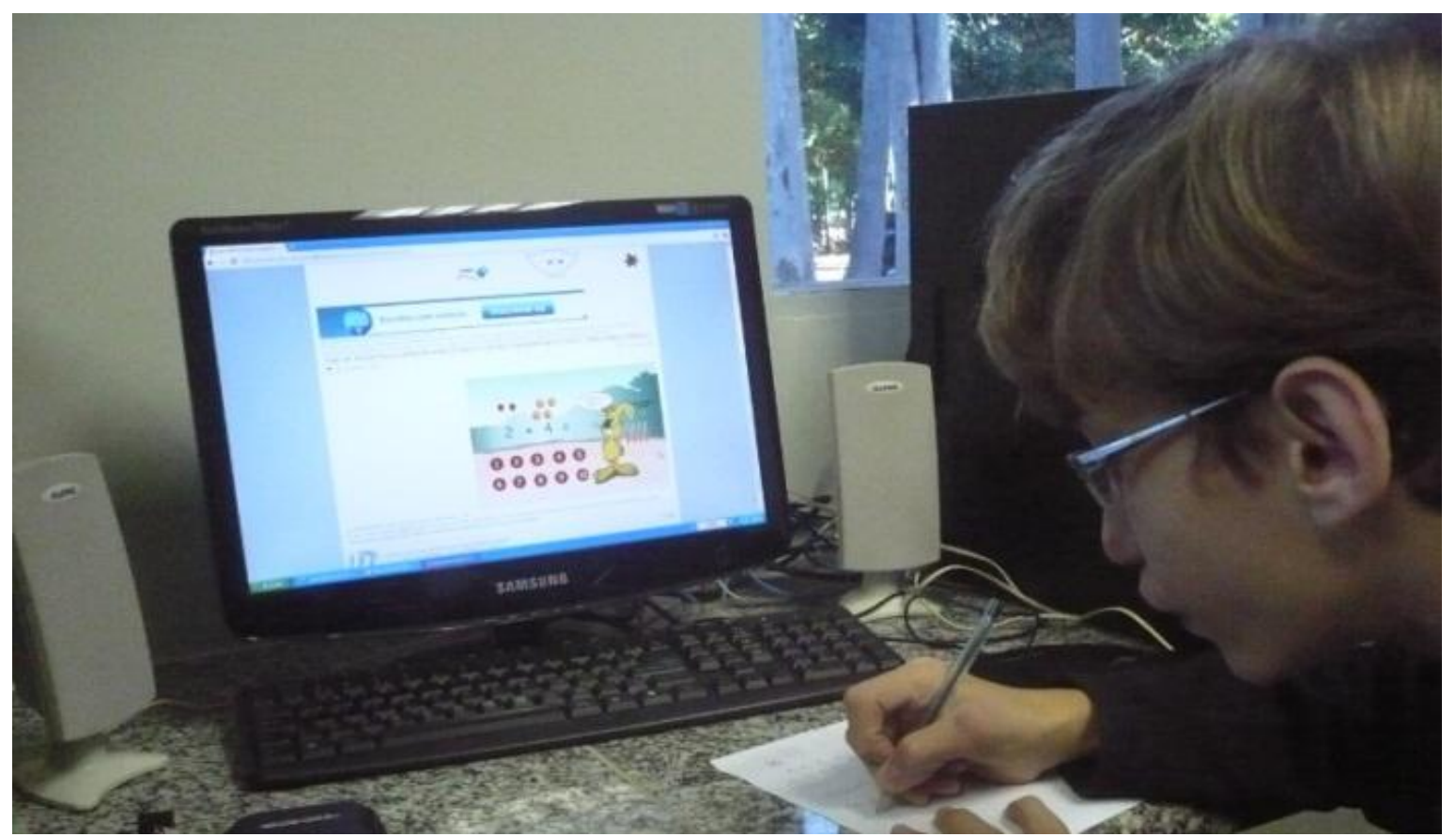

Figura 2. Aplicativo online de operações matemáticas 


\section{RESULTADOS E DISCUSSÃO}

A partir das atividades de intervenção com os estudantes, foram observados resultados preliminares. O aluno 1 (com Paralisia Cerebral) mora com sua mãe e frequentou a oitava série (atual nono ano) na Escola Estadual Professora Mirella Pesce Desidere, situada no município de Presidente Prudente/SP. É alfabetizado, e frequenta o setor de Fisioterapia em neurologia o Laboratório de psicomotricidade (LAPS) na FCT/UNESP. Com os fisioterapeutas o objetivo é estimular o esquema corporal, estimular a organização espaço temporal, estimular a motricidade global e fina.

As habilidades desse estudante se dá em uma grande capacidade de socialização algo que anteriormente o mesmo não estava acostumado, e uma facilidade em expor sua opinião sobre uma atividade proposta.

As dificuldades apresentadas, de acordo com a anamnese realizada, referem-se às quatro operações aritméticas (adição, subtração, divisão e multiplicação). Ou seja, o educando apresenta muita dificuldade em relação à compreensão dos conceitos matemáticos e, consequentemente não consegue avançar.

Com o objetivo de tentar minimizar ou até sanar estas dificuldades, desenvolvemos atividades partindo do assunto de interesse do educando que são carros e futebol privilegiando a sua alfabetização matemática, inclusão digital e social. Utilizamos o software educacional "Fazenda Rived" desenvolvido dentro do próprio grupo de pesquisa, que trabalha com as etapas do processo de alfabetização matemática de base, e peças do jogo Lego que trabalha com adição e subtração. 
A intervenção pedagógica com esse estudante foi elaborada a partir dos assuntos de interesse do mesmo. Neste caso, softwares educacionais e com o auxilio de outros materiais pedagógicos. Foi possível constatar que, até o momento, o estudante já apresenta avanços significativos na construção do conhecimento matemático e interpretação de texto, bem como no uso do computador. Ele passou a conhecer os números e realizar operações com os mesmos, diferentemente que ocorreu no início dos acompanhamentos. Além disso, percebemos que adquiriu certa autonomia na resolução dos exercícios propostos e no manuseio do computador. $\mathrm{O}$ estudante também teve avanços significativos em relação à adição e subtração de números naturais. Em relação à multiplicação e a divisão ainda estamos realizando as intervenções.

\section{CONCLUSÃO}

O trabalho realizado até o momento tem contribuído para amenizar ou até mesmo sanar dificuldades de aprendizagem ocasionadas por diferentes motivos, sejam elas de caráter biológico ou sociais. Nesse sentido, ressaltamos a importância de explorar as possibilidades e interesses de cada estudante, para que somente assim o mesmo obtenha um aprendizado significativo para toda sua vida. Com a obtenção de resultados positivos no processo de aprendizagem desses estudantes, consideramos que agora estão mais confiantes na realização das atividades pois adquiriram autonomia para resolução das mesmas.

Os EPAEE inseridos em um ambiente construcionista, contextualizado e significativo tiveram desenvolvimento positivo da aprendizagem, leitura e escrita. O uso de TA e TDIC permitem identificar que os estudantes adquirem autonomia, pois passam a construir suas ideias e comunicar-se. Por fim, ressaltamos que a TA pode auxiliar o professor na sala de recursos, possibilitando uma gama de recursos de acessibilidade. Trata-se de uma área do conhecimento e de atuação que engloba produtos, recursos, estratégias, práticas e serviços que pode propiciar aos EPAEE um ensino de qualidade.

\section{REFERÊNCIAS}

ABPC-Associação Brasileira de Paralisia Cerebral.Disponível em:< http://www.paralisiacerebral.org.br/saibamais06.php >. Acesso em: 25 de Maio 2011.

ASSOCIAÇÃO AMERICANA DE RETARDO MENTAL. Retardo mental definição, classificação e sistemas de apoio. Tradução Magda França Lopes. Porto Alegre: ARTMED, 10ae ed., 2006.

BERNARDI, J. Alunos com discalculia: O resgate da auto-estima e da auto-imagem através do lúdico.2006.189 f. Dissertação (Mestrado em Educação) Faculdade de Educação, Pontifícia 
Universidade Católica, Rio Grande do Sul.

BRASIL. Guia do Professor. Uma viagem Espacial. MEC/SEED. 2008.

SASSAKI,Romeu Kazumi. Inclusão: Construindo uma sociedade para todos. Rio de Janeiro: WVA, 1999.

SCHLÜNZEN, Elisa T. M. Mudanças nas práticas pedagógicas do professor: criando um ambiente construcionista, contextualizado e significativo para crianças com necessidades especiais físicas. 2000. 252 f. Tese (Doutorado em Educação). Pontifícia Universidade Católica de São Paulo, São Paulo.

KENSKI, V.M. Educação e Tecnologias: O Novo Ritmo da Informação. Campinas, SP: Papirus, 2007. SOUZA, A. M. C; FERRARETTO, I. Paralisia Cerebral: aspectos práticos. São Paulo, SP: Memnon, 1998. 